\title{
Scanning Kelvin Probe Investigation of High-Strength Steel Surface after Impact of Hydrogen and Tensile Strain
}

\author{
Andrei Nazarov * (D), Flavien Vucko and Dominique Thierry \\ French Corrosion Institute, 220 Rue Pierre Rivoalon, 29200 Brest, France; \\ flavien.vucko@institut-corrosion.fr (F.V.); dominique.thierry@institut-corrosion.fr (D.T.) \\ * Correspondence: Andrej.nazarov@institut-corrosion.fr; Tel.: +33-2980-515-52
}

Received: 6 January 2020; Accepted: 18 May 2020; Published: 20 May 2020

check for updates

\begin{abstract}
Hydrogen in combination with mechanical stress can lead to rapid degradation of high-strength steels through environmentally assisted cracking mechanisms. The scanning Kelvin probe (SKP) was applied to automotive martensitic steel grade MS1500 in order to detect local reactivity of the surface after hydrogen uptake and tensile deformation. Hydrogen and stress distribution in microstructures can be characterized by SKP indirectly measuring the potential drop in the surface oxide. Thus, the links between electron work function, oxide condition, and subsurface accumulation of hydrogen and stress have to be investigated. It was shown that plastic strain can mechanically break down the oxide film creating active (low potential) locations. Hydrogen effusion from the steel bulk, after cathodic charging in aqueous electrolyte, reduced the surface oxide and also decreased potential. It was shown that surface re-oxidation was delayed as a function of the current density and duration of cathodic hydrogen pre-charging. Thus, potential evolution during exposure in air can characterize the relative amount of subsurface hydrogen. SKP mapping of martensitic microstructure with locally developed residual stress and accumulated hydrogen displayed the lowest potential.
\end{abstract}

Keywords: scanning Kelvin probe; high-strength steel; hydrogen effusion; oxidation; tensile strain

\section{Introduction}

Hydrogen directly affects metallic materials by degrading their mechanical properties. Hydrogen-assisted cracking (HAC) limits the application of high-strength steels (HSS) in different branches of industry, such as the transport industry, because their sensitivity to cracking increases proportionally with their strength [1-3]. High-strength steel fasteners or automotive high-strength steel sheets may fail due to hydrogen-delayed fracture mechanisms. In the absence of residual stresses or external loading, this environmental hydrogen can reduce ductility and create blisters and internal cracks. Additionally, with the application of tensile stress with a stress intensity factor exceeding a specific threshold, the hydrogen induces subcritical cracks, whose growth leads to failure [4-6].

Corrosion of steel or its metallic protective coating is the main source of hydrogen under service conditions. It is well established that to induce HAC, critical diffusible hydrogen content in the HSS, which is a function of local stress, must be reached [7-10]. The locations which are prone to cracking are close to the corroding surface containing the highest hydrogen concentration (Figure 1) [8].

The resistance of an alloy to HAC is strongly affected by the interaction of hydrogen with the microstructural heterogeneities that act as hydrogen traps [11-13]. It was found that reversible (low-binding energy) traps often impart a degree of high susceptibility to HAC [12]. The hydrogen concentration increases with increasing deformation and, thus, also with an increasing amount of dislocations [12]. 


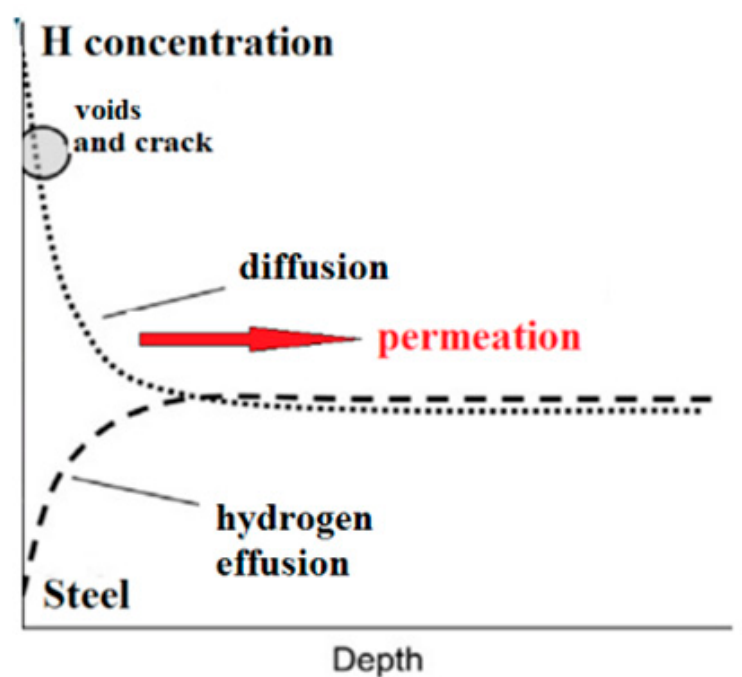

Figure 1. Schematic of the hydrogen depth distribution close to a steel surface. With permission from Elsevier Ltd. 2010 [8].

The schematic in Figure 1 shows that increased hydrogen concentration was found at the alloy surface or subsurface. To obtain further insight, localized surface-sensitive methods have been used to determine the distribution of hydrogen and the amount of stress close to the steel subsurface [14-21]. It was suggested $[16,22]$ that the scanning Kelvin probe (SKP) and scanning Kelvin probe force microscopy (SKPFM) are currently the most sensitive techniques available and can detect extremely low quantities of hydrogen. The main interest is a possible application for the local quantification of hydrogen and its distribution close to the steel surface as a function of the microstructure, hydrogen traps, and stress $[16,20,21]$. One of the approaches for quantification links the ability of hydrogen to chemically reduce the oxide film with the electron work function (potential) [20-24]. Using this approach, the SKP was applied to determine the hydrogen diffusivity in hardened martensitic steels [24-26].

SKPFM with high spatial resolution showed that dislocation and vacancies at the interface matrix/oxide are the main hydrogen trapping sites in ferritic steel [16]. SKPFM is an effective technique to find the locations of hydrogen enrichment and developing pits or cracks in these locations [27,28]. It was shown that crack propagation is promoted by hydrogen enrichment of crack tip induced by stress [28]. SKPFM can compare the changes in topography and electron work function due to hydrogen uptake. It was observed that locations of low-electron work function related to hydrogen accumulation create the nano-bulges [28]. Thus, hydrogen local enrichment decreases the cohesion forces between atoms that lead to mechanical rupture and then propagation of microcracks [28].

The influence of the mechanical strain on the electron work function of different steels was investigated in previous works [29-32]. It was found that tensile strain creates breaks in the oxide film due to the emerging of dislocations and dislocation slip steps at the alloy surface. Potential SKP mapping detects these low potential locations, which are directly related to defects in oxide films.

For assessment of hydrogen and stress, SKP and SKPFM measure the local electron work function that is related to the conditions (thickness, degree of oxidation) of the surface oxide. Using these techniques, hydrogen and stress only indirectly can be characterized in microstructures. Thus, the links between local electron work function (potential), state of the oxide, concentration of the subsurface hydrogen, and level of residual stress, must be investigated in detail. It can help in further understanding their interaction at the local level. In this work the effect of hydrogen effusion (Figure 1) on the oxidation of an alloy surface in the air was studied. In addition, SKP was used to visualize the distribution of the strain in high-strength steel. Thus, locations with increased activity of the electrons in pre-strained and hydrogen pre-charged samples can be determined. 


\section{Materials and Methods}

\subsection{Materials and Surface Treatment}

Specimens of cold-rolled automotive grade MS1500 steel plates (HSS) with a thickness of $0.8 \mathrm{~mm}$ were used in the tensile and hydrogen uptake experiments. The chemical composition of the steel is shown in Table 1 and the nominal mechanical properties determined according to ASTM E8/E8M standard [33] are presented in Table 2. Specimens were cut from plates using laser cutting. Two sides of the samples were ground down to $\mathrm{P} 4000$ by $\mathrm{SiC}$ paper, then degreased in acetone using an ultrasonic bath, rinsed in deionized water, and then dried by compressed air. To stabilize the surface oxide after polishing, the samples were aged in an oven at $100{ }^{\circ} \mathrm{C}$ for $1 \mathrm{~h}$.

Table 1. Nominal compositions of the investigated materials (wt.\%).

\begin{tabular}{ccccccccc}
\hline Material & Fe & C & Si & Mn & P & S & Al & Nb + Ti \\
\hline MS 1500 & Bal. & $<0.3$ & $<0.4$ & $<0.1$ & $<0.02$ & 0.01 & $>0.015$ & $<0.1$ \\
\hline
\end{tabular}

Table 2. Mechanical properties of MS 1500 and SAE 1008 steels.

\begin{tabular}{cccc}
\hline Material & Yield Strength (MPa) & Ultimate Tensile Strength (MPa) & Elongation (\%) \\
\hline MS1500 & 1200 & 1500 & 7 \\
\hline
\end{tabular}

The microstructure of HSS was fully martensitic with carbide precipitates and prior austenite grain size in the range of 5-10 $\mu \mathrm{m}$. The dimensions of the samples for the study of hydrogenation were $30 \mathrm{~mm} \times 30 \mathrm{~mm} \times 0.8 \mathrm{~mm}$ and the tensile samples had gauge area dimensions of $10 \mathrm{~mm} \times 10 \mathrm{~mm}$. To develop local tensile strain the tensile specimen was strained using a hydraulic tensile machine Zwick HC25 (ZwickRoell, Ulm, Germany) at a constant strain rate of $1 \times 10^{-3} \mathrm{~s}^{-1}$.

\subsection{Electrochemical Treatment}

To study the effect of hydrogen absorption on the potential of steel, cathodic charging of the electrode was carried out. It was simply immersed in $0.1 \mathrm{M} \mathrm{NaOH}$ aqueous electrolyte and cathodically polarized using the current densities of $-5 \mathrm{~mA} / \mathrm{cm}^{2}$ and $-25 \mathrm{~mA} / \mathrm{cm}^{2}$. The setup included a three-electrode cell containing a working electrode (steel plate $30 \mathrm{~mm} \times 30 \mathrm{~mm} \times 0.8 \mathrm{~mm}$ ), a counter $\mathrm{Pt}$-mesh, and a reference $\mathrm{Hg} / \mathrm{HgO}$ electrode. After treatment, the specimen was rinsed with deionized water and then was dried in a stream of dry air. The tensile specimens preliminary pre-strained under laboratory conditions were also used. The total time between the final grinding and the beginning of SKP measurement was ca. 5 min.

To study the effect of permeated hydrogen on the potential of the steel surface, the steel membrane was cathodically polarized from one side. After treatment, the sample was moved to SKP to study the side of the membrane opposite to treated.

\subsection{SKP Setup for Analysis of Stress and Hydrogen}

SKP measures the contact potential difference between two metallic electrodes (the working and the probe) separated by an air gap. The potential of the probe is calibrated which makes it possible to determine the potential of the working electrode and apply a convenient electrochemical scale. In this study, a height controlled SKP instrument from Wicinski-Wicinski GbR (Erkrath, Germany) was used. The reference electrode was a $\mathrm{CrNi}$ alloy needle with a tip diameter of $100 \mu \mathrm{m}$, vibration frequency of $9.8 \mathrm{~Hz}$, and the distance to the working electrode surface was approximately $50 \mu \mathrm{m}$. Surface contour mapping (topographic profile) was carried out simultaneously with the potential mapping. The measurements were performed in ambient air at 50\%-60\% relative humidity (RH) and $22 \pm 1{ }^{\circ} \mathrm{C}$, which were defined as laboratory conditions. Prior to the measurement, the potential of the 
probe was calibrated above a saturated $\mathrm{Cu} / \mathrm{CuSO}_{4}$ electrode; all potentials are provided against the standard hydrogen electrode (SHE). To verify the stability of the potential of SKP tip, the calibration was additionally checked after the experiment. The SKP measurements in-situ, polarizing the working electrode using potentiostat, involved a strong noise and this setup was difficult to apply. Thus, all SKP measurements were performed ex-situ after surface treatment of HSS.

\section{Results and Discussion}

\subsection{Potential Distribution above HSS after Grinding.}

To determine the links between potential and the state of the surface oxide, SKP was used to measure the evolution of the steel potential after oxide removal. The potential map (Figure 2A) of the HSS sample was scanned within $5 \mathrm{~min}$ after grinding. The speed of scanning was $0.4 \mathrm{~mm} / \mathrm{s}$ and the densities of points were $50 \mathrm{~mm}$ (X-axis) and $200 \mathrm{~mm}$ (Y-axis). The native oxide film was removed and the exposure in air during the period of measurements $(125 \mathrm{~min})$ led to the growth of a new oxide film, which was accompanied by a corresponding increase in the measured potential from $50 \mathrm{mV}$ to approximately $150 \mathrm{mV}$ (SHE).
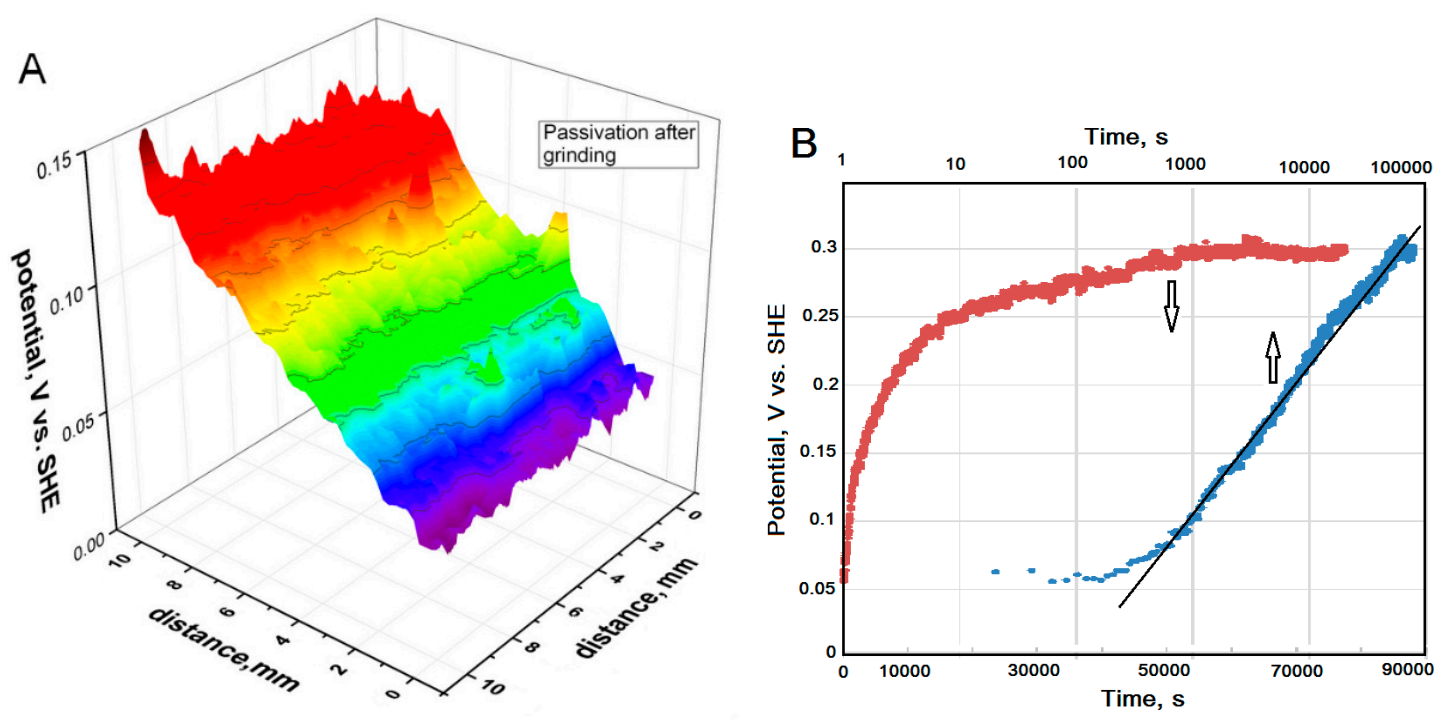

Figure 2. (A) Potential map of high-strength steel (HSS) surface after grinding with time of scanning at $125 \mathrm{~min}$. (B) Monitoring of the potential taken above the surface of HSS after grinding plotted in direct and in semi-logarithmic coordinates.

The oxidation of the steel under atmospheric conditions after grinding can be monitored at one point on the surface (Figure 2B). Over the course of the exposure to the atmosphere, the dependence of the potential vs. time asymptotically returns to the initial, pre-grinding potential of the surface near $0.3 \mathrm{~V} / \mathrm{SHE}$. When using semi-logarithmic coordinates, the plot of the potential vs. time was a straight line (Figure 2B). The potential can be considered as proportional to the oxide thickness. In aqueous electrolytes the thickness of the oxide layer on the iron surface at the steady state is a linear function of potential [34]. The direct correlation between potential measured by SKP and the oxide thickness measured by glow discharge optical emission spectroscopy was obtained for stainless steel [30]. The power law of oxide growth (Figure 2B) shows that the mass and charge transport occur in the oxide layer assisted by high field migration of defects or species (e.g., oxygen vacancies). According to X-ray photoelectron spectroscopy data [35], the oxide films formed on the iron surface in the humid atmosphere consist of interlayer $\mathrm{Fe}_{3} \mathrm{O}_{4}$ and a top layer of $\mathrm{FeOOH}$, and oxidation in dry air completes the $\mathrm{Fe}_{2} \mathrm{O}_{3}$ top layer. The thicknesses of the oxide films formed in humid and dry atmospheres were $2 \mathrm{~nm}$ and $3.5 \mathrm{~nm}$, respectively [35]. 


\subsection{Effect of Tensile Strain on the Distribution of the Potential above HSS}

The effect of tensile strain on the potential of mild steel tensile samples was described elsewhere [36]. The plastic tensile deformation generated dislocations and dislocation pileups. The emergence of the dislocations at the mild steel surface and the formation of the slip bands broke down the surface oxide, which created locations with decreased potential [36]. Thus, plastic strain close to $15 \%$ decreased potential in a central (gauge) section of 150-200 mV. Afterward, the contact of the newborn surfaces with air increased the potential due to the growth of a new oxide film. It was additionally evidenced by atomic force microscopy, scanning electrochemical microscopy, and local electrochemical impedance spectroscopy $[30,31,36]$.

SKP was used to investigate the distribution of the potential above a gauge section of HSS tensile samples after the application of strain (Figure 3). HSS exhibited a low limit for elongation to fracture of ca. $7 \%$ (Table 2). The potential distribution across the gauge section of HSS after the application of $6 \%$ of plastic strain resulted in necking at the center of the sample. The necking area of the surface was observed visually and in a topographic profile (depth $40 \mu \mathrm{m})$. An area of low potential related to the necked area was found in the potential map (Figure 3B). Fresh surface areas, formed by the dislocations and slip bands, decreased the potential by $150 \mathrm{mV}$. Exposure in ambient air slowly increased the potential in the strained area and the potential difference increased by about $100 \mathrm{mV}$ as a result of the re-oxidation (Figure 3C). A similar passivation process took place after surface grinding (Figure 2B). However, the deformed area, even after $24 \mathrm{~h}$ of exposure in air, exhibited a potential that was $80-90 \mathrm{mV}$ lower than the potential of the non-altered surface (Figure 3C). The electrochemistry of freshly created surfaces developed Burstein and Kearns [37] showed accelerated hydrogen-reduction kinetics relative to the oxide-covered areas of the steel surface. Even without external load, the residual stress in the bulk might also influence hydrogen uptake in the steel as discussed by Lufrano and Sofronis [38]. From a particular study it can be concluded that SKP can determine the locations with increased surface reactivity as a result of tensile straining of HSS.
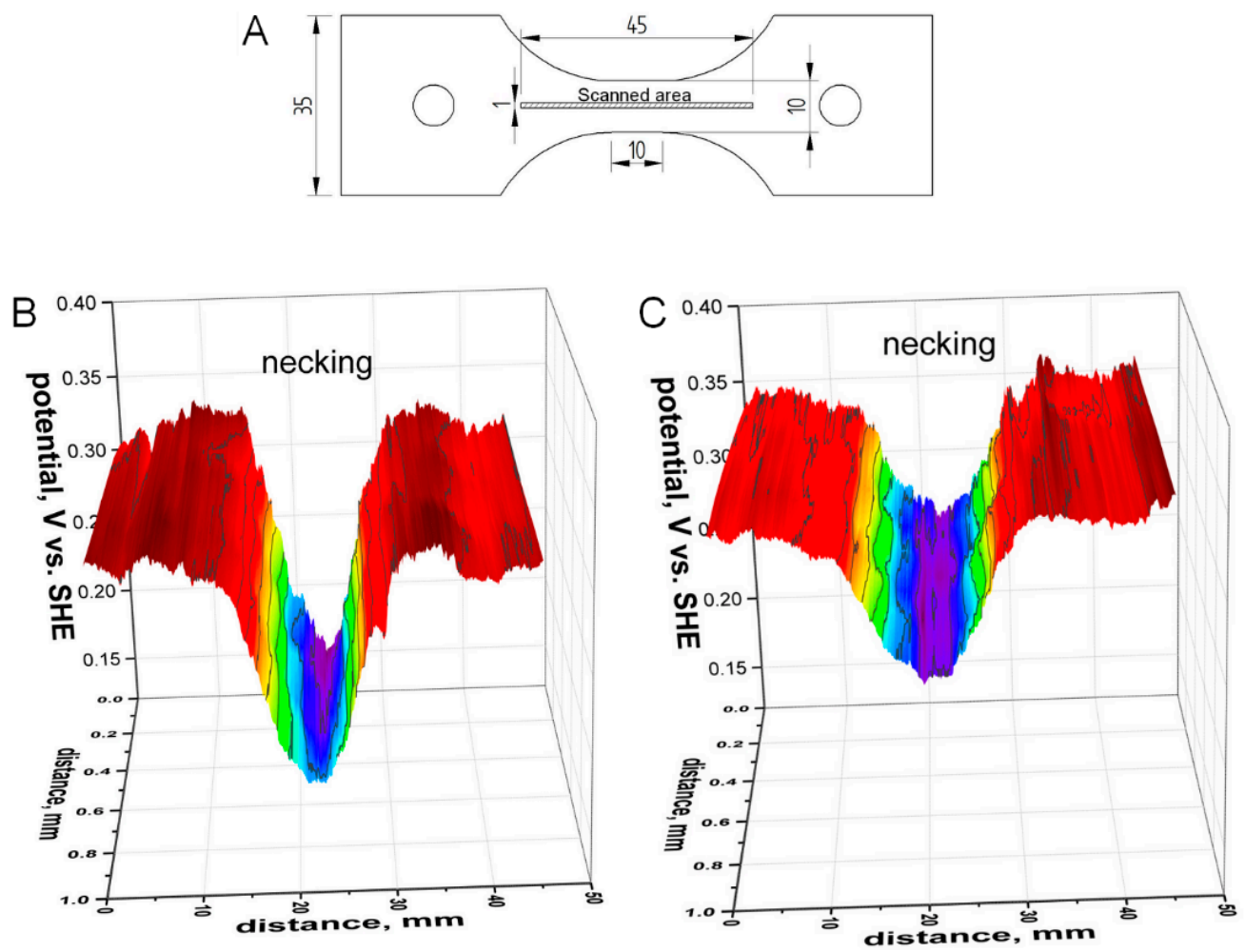

Figure 3. Schematic of the tensile sample (A), potential distribution across a gauge section of HSS after a plastic strain of $6 \%$, within (B) $0.5 \mathrm{~h}$ and (C) $24 \mathrm{~h}$ of strain application. 


\subsection{SKP Assessment of Steel Surface after Cathodic Polarization in $0.1 \mathrm{M} \mathrm{NaOH}$ Aqueous Electrolyte}

Hydrogen-assisted cracking is a result of interplay between stress and subsurface hydrogen. SKP was mainly used to quantify hydrogen in steels coated by Pd films [20-22]. However, HSS surface reactivity as a function of the efficiency of hydrogen uptake was not studied systematically. The SKP surface assessment was carried out after cathodic hydrogen charging of steel MS1500 in a $0.1 \mathrm{M} \mathrm{NaOH}$ aqueous electrolyte. The sample was ground and cathodically polarized using a current density of $-5 \mathrm{~mA} / \mathrm{cm}^{2}$ for $133 \mathrm{~min}$. SKP potential mapping was carried out in the air within $5 \mathrm{~min}$ after cathodic hydrogen charging (Figure 4A). Compared with profiles from Figure 2A of HSS after grinding, it was possible to demonstrate that cathodic polarization and hydrogen inserted in the microstructure significantly decreased the potential, which can be linked to oxide reduction and a decreased rate of oxide film formation [23-26]. The profile shown in Figure 4B was measured after 1440 min of exposure in air and had a potential distribution of $180 \pm 30 \mathrm{mV}$ (SHE). This potential was lower than the initial potential of $290 \pm 20 \mathrm{mV}$ (SHE).
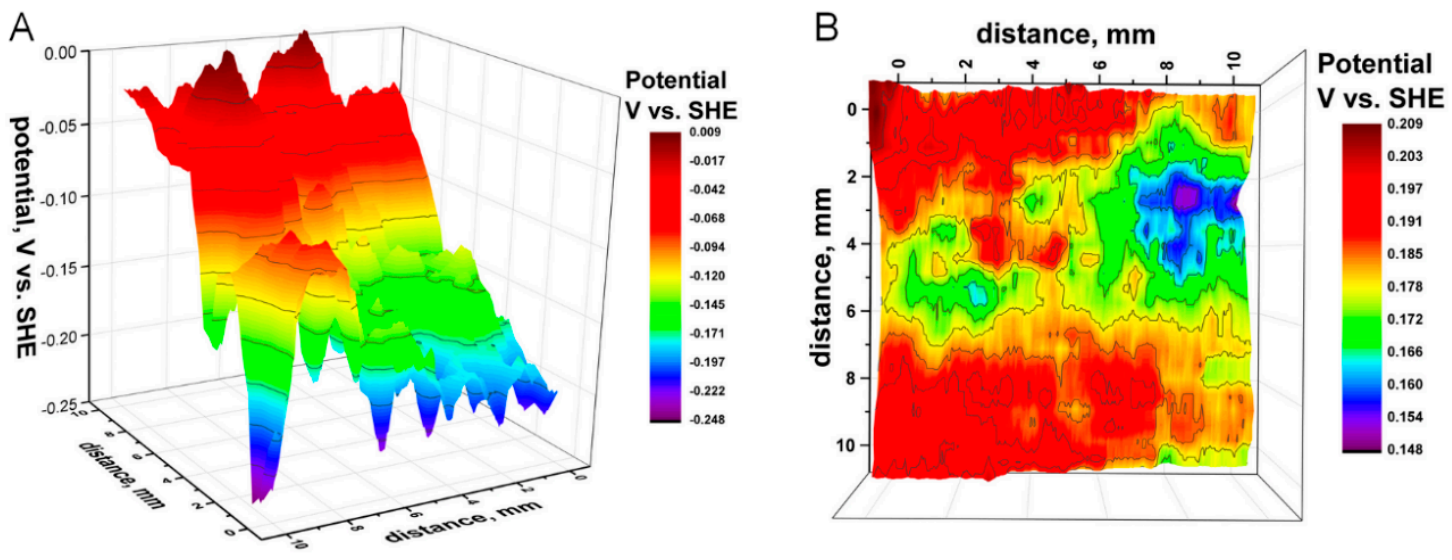

Figure 4. Potential distribution above HSS measured after surface grinding and cathodic polarization with a current density of $-5 \mathrm{~mA} / \mathrm{cm}^{2}$ for a duration of $8 \mathrm{ks}$ (133 $\mathrm{min}$ ). (A) Five min after surface treatment and (B) 1440 min after treatment.

The potential change after grinding and after grinding followed by cathodic polarization is presented in Figure 5 in semi-logarithmic coordinates. In linear coordinates, the curves look like those shown in Figure 2B. The potential for the hydrogen charged surfaces was lower than the potential of recently-ground surfaces. The increase of the duration of the cathodic charging decreased initial potential measured after treatment. It can be attributed to an increased subsurface hydrogen concentration and thinner oxide film. Two slopes were found in the passivation dependencies of the pre-charged surfaces (Figure 5). After initial potential delay, relatively quick potential increase can be attributed to oxide growth controlled by hydrogen emerging from low-energy traps. Later, the passivation kinetics are similar to that of pre-ground steel and the oxide-hydroxide film thickening can be controlled by species migration in the oxide film.

Previous experiments related to the conditions of relatively mild hydrogen absorption. To study the surface properties more related to hydrogen-assisted cracking, a cathodic current density of $-25 \mathrm{~mA} / \mathrm{cm}^{2}$ was applied for 266 and $1400 \mathrm{~min}$ in $0.1 \mathrm{M} \mathrm{NaOH}$. After charging, rinsing in deionized water, and quick drying in a stream of dry air, the potential at one point of the surface was monitored (Figure 6A). The surfaces exhibited low potentials (Figures 5 and 6 ) in the range of -0.3 to $-0.35 \mathrm{~V} / \mathrm{SHE}$, which seeks to the standard reversible potential for a $\mathrm{Fe} / \mathrm{Fe}^{2+}$ electrode $(-0.44 \mathrm{~V}$ vs. SHE). This showed that the surface was nearly oxide-free. Exposure in the air increased the potential which can be a result of the formation of surface oxide. However, the surface potential remained low for a relatively long period which can be related to the effect of subsurface hydrogen. Thus, in a particular setups, 
hydrogen is affected on the surface oxide (Figures 5 and 6A) strongly comparing with the mechanical removal of the oxide by grinding or by application of tensile plastic strain (Figures 2 and 3).

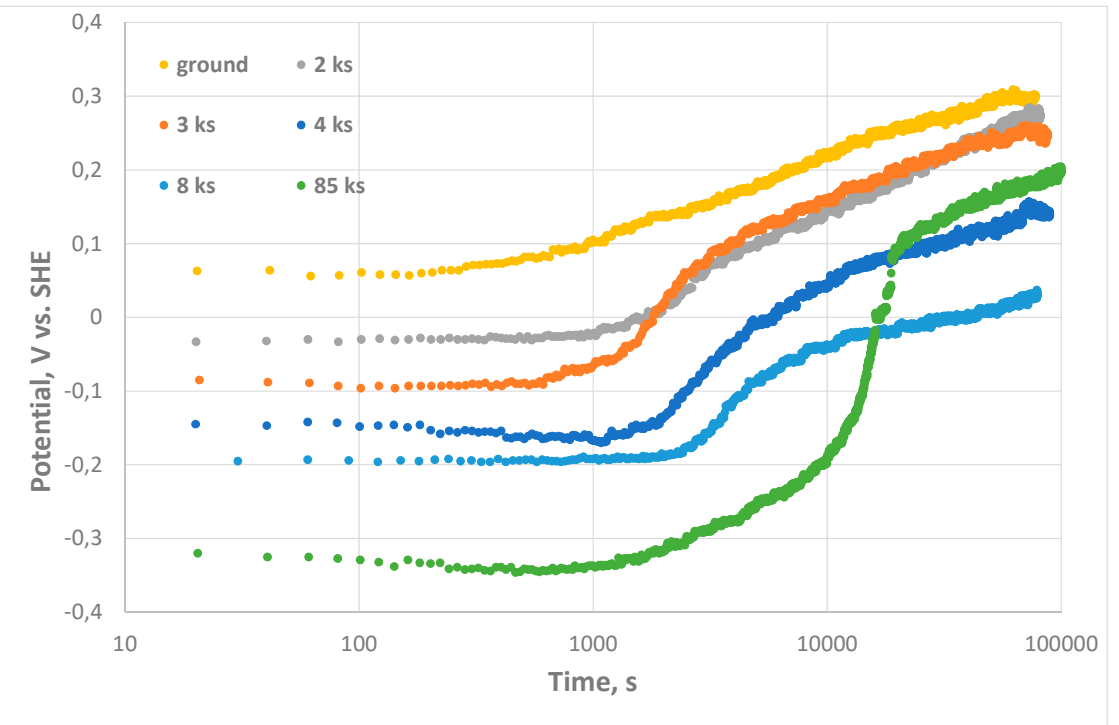

Figure 5. Potential monitoring after surface grinding (reference) and grinding followed by cathodic treatment with a current density of $-5 \mathrm{~mA} / \mathrm{cm}^{2}$ for $2 \mathrm{ks}, 3 \mathrm{ks}, 4 \mathrm{ks}, 8 \mathrm{ks}$, and $85 \mathrm{ks}$.
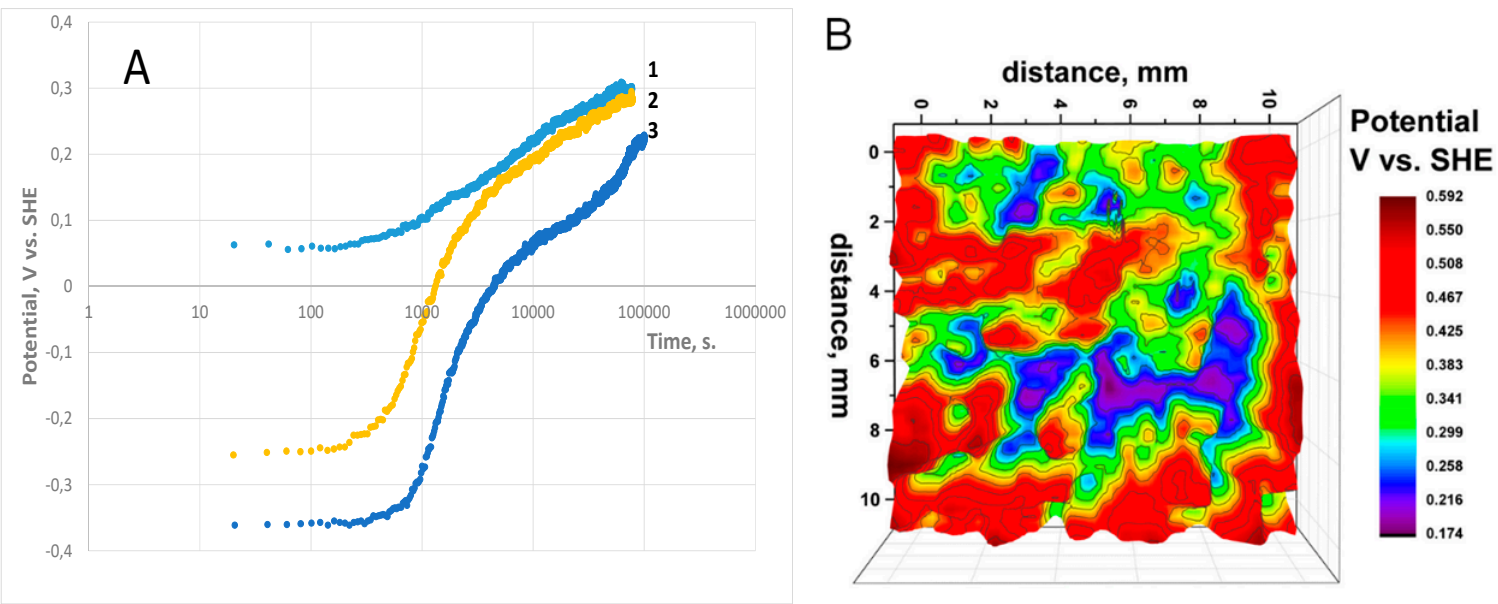

Figure 6. (A) Monitoring of potential in ambient air at room temperature after grinding (1) and hydrogen charging at $-25 \mathrm{~mA} / \mathrm{cm}^{2}$ in $0.1 \mathrm{M} \mathrm{NaOH}$ solution during $4 \mathrm{ks}$ (2) and $85 \mathrm{ks}$ (3). (B) Potential distribution after cathodic charging during $85 \mathrm{ks}$ and exposure in air.

Three days after the cathodic treatment and oxidation in dry air, the map of potential was measured (Figure 6B). The potential distribution was extremely non-uniform and the potential difference between locations with low and high potentials reached as high as $400 \mathrm{mV}$. In some locations, the potential had a low value, which can be the result of the interaction of subsurface hydrogen with a steel matrix at a local state. The locations that were more positive than the initial potential of $0.3 \mathrm{~V}$ (SHE) can be attributed to an increased thickness of the oxide-hydroxide film (Figure 6B). During exposure in air, the absorbed atomic hydrogen can reduce the $\mathrm{Fe}^{3+}$ species to $\mathrm{Fe}^{2+}$. On the other hand, oxygen in air can oxidize $\mathrm{Fe}^{2+}$ to $\mathrm{Fe}^{3+}[20,23,25]$. Thus, the impacts of hydrogen and oxygen can lead to the local thickening of the surface oxide.

According to literature data [12], the emission of hydrogen from the steel after cathodic polarization can continue for about $1 \mathrm{~h}$. However, the thickness of the steel membrane, density, and energy of 
trapping sites drive the desorption rate and complete desorption could last a few hours for martensitic or ferritic steels. Interaction of an active steel surface with the oxygen of air can increase the thickness of the oxide/hydroxide layer, depending on the hydrogen concentration and the kind of traps near the steel surface.

\subsection{SKP Study of HSS Surface Interaction with Permeated Hydrogen}

In the experiments given above, the hydrogen effused from interstitial locations and low-energy traps close to the steel surface. To get information about hydrogen permeated into alloy bulk, the SKP measurements have to be provided at the side of the steel membrane opposite the polarized one. The hydrogen entry side of the steel membrane $(0.8 \mathrm{~mm}$ thick) was polarized in $0.1 \mathrm{M} \mathrm{NaOH}$ using a current density of $-5 \mathrm{~mA} / \mathrm{cm}^{2}$ for durations of 8 and $16 \mathrm{ks}$. SKP was used to monitor the potential of the opposite side within $5 \mathrm{~min}$ after treatment (Figure 7). Initial potentials were in the range of $0.16-0.18 \mathrm{~V} / \mathrm{SHE}$. Polarization with an increased current density of $-10 \mathrm{~mA} / \mathrm{cm}^{2}$ and a duration of $90 \mathrm{ks}$ did not change this value (Figure 7). These potentials are significantly nobler than the potentials measured on the direct side, which were in the range of -0.2 to $-0.3 \mathrm{~V} / \mathrm{SHE}$ (Figure 5). This could be caused by hydrogen diffusion limitations and lower hydrogen concentration in the traps on the detection side. The passivation kinetics was similar to the surface grinding case (Figure 7). During polarization, the detecting side contacted with air and SKP mapping showed uniform potential distribution. The results showed that in this case, there was no significant hydrogen amount effused from the alloy bulk after cathodic charging. However, it is possible to note that time delay before the potential started to increase is in the range of 5-10 ks. From electrochemical permeation tests performed according to ISO 17081:2014 standard [39] (not reported here), the complete desorption of hydrogen from the detection side of $0.8 \mathrm{~mm}$ thick MS1500 steel sample after cathodic charging using the same conditions as for SKP data was typically in the range of 1.5 to $2 \mathrm{~h}$. It is close to SKP measurements of time delay (Figure 7).

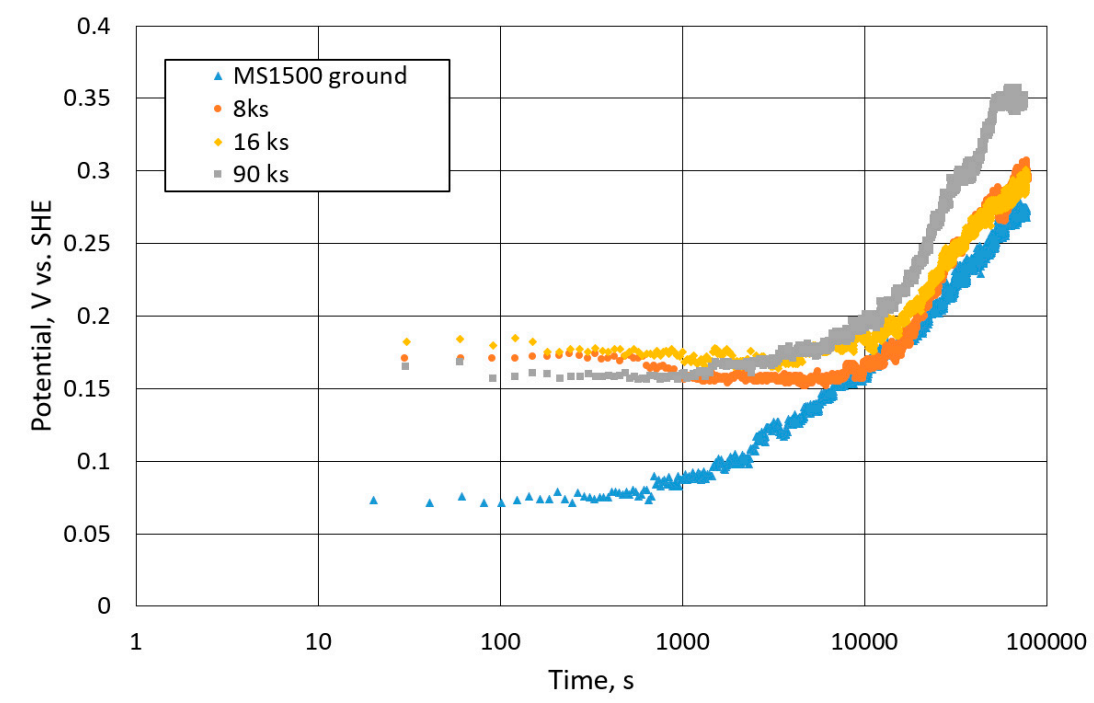

Figure 7. Scanning Kelvin probe (SKP) monitoring of the potential measured at opposite side of a HSS membrane after galvanostatic cathodic polarization $(0.1 \mathrm{M} \mathrm{NaOH})$ of the working side at $-5 \mathrm{~mA} / \mathrm{cm}^{2}$ for durations of $8 \mathrm{ks}$ and $16 \mathrm{ks}$ and $-10 \mathrm{~mA} / \mathrm{cm}^{2}$ for duration of $90 \mathrm{ks}$. The dependence of the passivation after grinding is shown as a reference.

\subsection{SKP Assessment of Stress and Hydrogen in Tensile HSS Sample}

The important goal of this research was to study the interaction of absorbed hydrogen created by cathodic water reduction with pre-strained HSS surfaces. The initial potential distribution of the tensile specimen was flat and in the range of 380-395 mV/SHE. Then, $6 \%$ plastic strain was applied 
to the sample by tensile testing. A location with low potential, related to the necking of the sample, was found in the SKP map (Figure 8A). The potential dropped for $150 \mathrm{mV}$ which corresponds to the data of Figure 3. Cathodic polarization with a current density of $-25 \mathrm{~mA} / \mathrm{cm}^{2}$ and a duration of $4 \mathrm{ks}$ was applied to the whole surface of the sample. The monitoring of potential during hydrogen effusion for a non-strained sample in air was shown in Figure 6A. Initially the potential distribution for a tensile pre-strained sample was uniform at $-0.25 \mathrm{~V}$ (SHE). The map in Figure $8 \mathrm{~B}$ was obtained after exposure in air that decreased the potential in the area of necking. This was likely caused by surface activation by the hydrogen stored in the area of plastic deformation $[12,18,38,40]$. Thus, SKP confirmed that the plastically deformed area possessed an excess of hydrogen stored in trapped locations, such as the dislocations. This observation is in line with SKPFM measurement of the area containing a slip deformation part and cracked part on SUS 304 stainless steel [40]. This area accepted low potentials due to the accumulation of hydrogen.
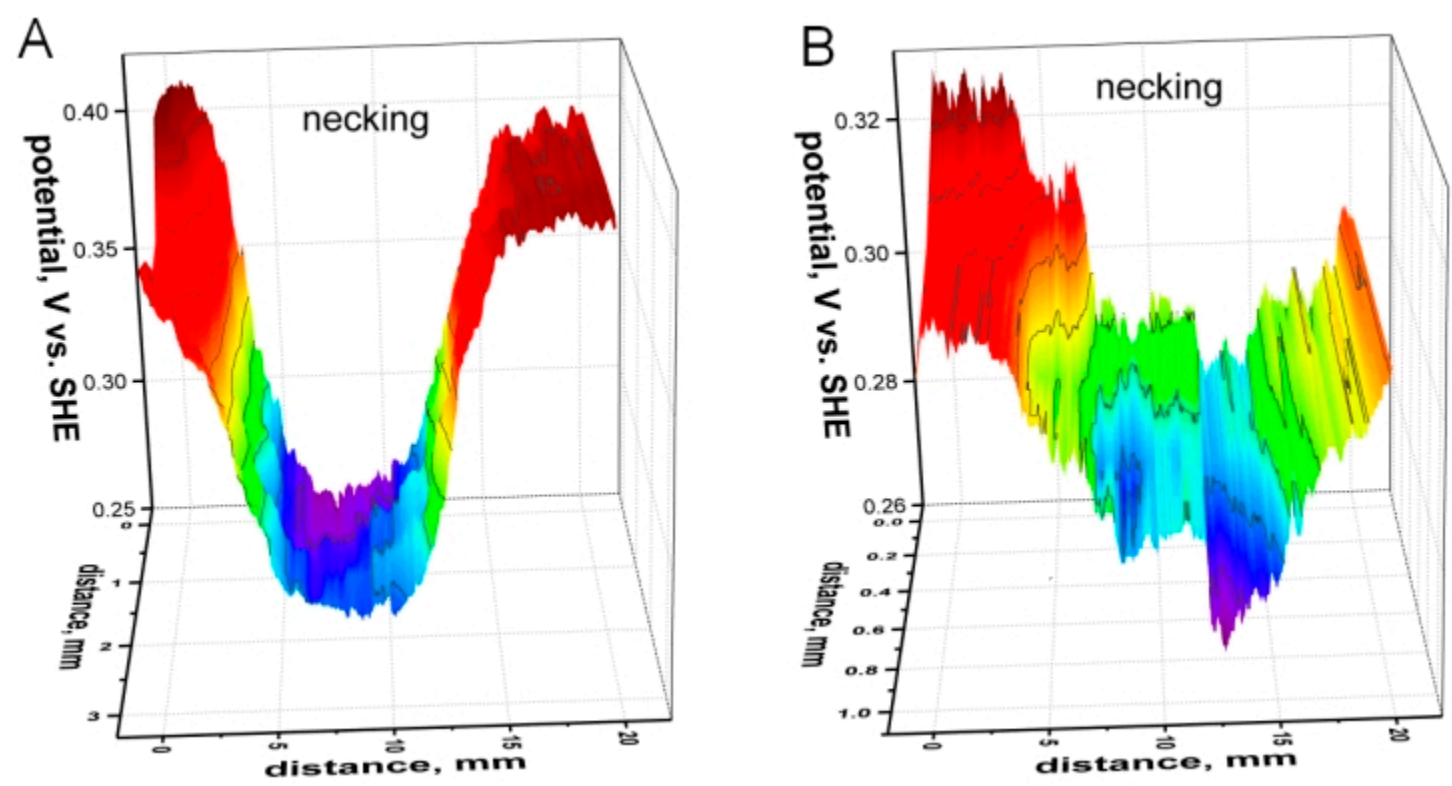

Figure 8. Potential profiles for a tensile sample of HSS after tensile straining (A), and after cathodic polarization in an aqueous electrolyte and $24 \mathrm{~h}$ of exposure in air (B).

\section{Conclusions}

1. The effect of tensile deformation on the potential of the high-strength steel was measured. Plastic strain $(6 \%)$, close to the level to fracture, locally decreased the potential for $150 \mathrm{mV}$ and exposure in air increased the potential. This is the result of the surface oxide breaking down with the following oxidation of the deformed surface.

2. The potential of specimen was monitored after cathodic hydrogen charging. Hydrogen effusion initially decreased the potential of steel for $300-500 \mathrm{mV}$ and exposure in air and growth of surface oxide increased the potential. Effusion of subsurface hydrogen delayed the oxidation as a function of current density and duration of cathodic charging. Non-uniform distribution of the potential related to different surface reactivity was found for the case of charging with high current density.

3. Hydrogen pre-charged or pre-strained surfaces showed prolonged electron reactivity. Locations containing residual stress and absorbed hydrogen showed the lowest potential (electron work function).

Author Contributions: Conceptualization, A.N. and D.T.; methodology, A.N. and F.V.; software, F.V.; validation, F.V.; formal analysis, A.N.; investigation, A.N. and F.V.; writing-original draft preparation, A.N.; writing-review and editing, A.N. and D.T.; visualization, F.V.; supervision, D.T.; project administration, D.T.; funding acquisition, D.T. All authors have read and agreed to the published version of the manuscript. 
Funding: This research received no external funding.

Conflicts of Interest: The authors declare no conflict of interest.

\section{References}

1. Omura, T.; Kudo, T.; Fujimoto, S. Environmental Factors Affecting Hydrogen Entry into High Strength Steel due to Atmospheric Corrosion. Mater. Trans. 2006, 47, 2956-2962. [CrossRef]

2. Tsuru, T.; Huang, Y.; Ali, M.R.; Nishikata, A. Hydrogen entry into steel during atmospheric corrosion process. Corros. Sci. 2005, 47, 2431-2440. [CrossRef]

3. So, K.H.; Kim, J.S.; Chun, Y.S.; Park, K.T.; Lee, Y.K.; Lee, C.S. Hydrogen delayed fracture properties and internal hydrogen behaviour of a Fe-18Mn-1.5Al-0.6C TWIP steel. ISIJ Int. 2009, 49, 1952-1959. [CrossRef]

4. Hirth, J.P. Effects of hydrogen on the properties of iron and steel. Metall. Mater. Trans. A 1980, 11, 861-890. [CrossRef]

5. Chiaberge, M. New Trends and Developments in Automotive System Engineering, High Mn TWIP Steels for Automotive Applications; De Cooman, B.C., Chin, K.G., Kim, J.K., Eds.; InTech: Rijeka, Croatia, 2011; pp. 101-128.

6. Liu, Z.Y.; Li, X.G.; Cheng, Y.F. Mechanistic aspects of near-neutral stress corrosion cracking of pipelines under cathodic polarization. Corros. Sci. 2012, 55, 54-60. [CrossRef]

7. Wang, M.; Akiyama, E.; Tsuzaki, K. Determination of the critical hydrogen concentration for delayed fracture of high strength steel by constant load test and numerical calculation. Corros. Sci. 2006, 48, 2189-2202. [CrossRef]

8. Akiyama, E.; Matsukado, K.; Wang, M.; Tsuzaki, K. Evaluation of hydrogen entry into high strength steel under atmospheric corrosion. Corros. Sci. 2010, 52, 2758-2765. [CrossRef]

9. Sanchez, J.; Lee, S.F.; Martin-Rengel, M.A.M.; Fullea, J.; Andrade, C.; Ruiz-Hervias, J. Measurement of hydrogen and embrittlement of high strength steel. Eng. Fail. Anal. 2016, 59, 467-477. [CrossRef]

10. Nanninga, N.; Grochowsi, J.; Heldt, L.; Rundman, K. Role of microstructure, composition and hardness in resisting hydrogen embrittlement of fastener grade steels. Corros. Sci. 2010, 52, 1237-1246. [CrossRef]

11. Cabrini, M.; Sinigaglia, E.; Spinelli, C.; Tarenzi, M.; Testa, C.; Bolzoni, F.M. Hydrogen Embrittlement Evaluation of Micro Alloyed Steels by Means of J-Integral Curve. Materials 2019, 12, 1843. [CrossRef]

12. Pérez Escobar, D.; Depover, T.; Duprez, L.; Verbeken, K.; Verhaege, M. Combined thermal desorption spectroscopy, differential scanning calorimetry, scanning electron microscopy and X-ray diffraction study of hydrogen trapping in cold deformed TRIP steel. Acta Mater. 2012, 60, 2593-2605.

13. Frappart, S.; Feaugas, X.; Creus, J.; Thebault, F.; Delattre, L.; Marchebois, H. Hydrogen solubility, diffusivity and trapping in a tempered $\mathrm{Fe}-\mathrm{C}-\mathrm{Cr}$ martensitic steel under various mechanical stress states. Mater. Sci. Eng. A 2012, 534, 384-393. [CrossRef]

14. Koyama, M.; Rohwerder, M.; Tasan, C.C.; Bashir, A.; Akiyama, E.; Takai, K.; Raabe, D.; Tsuzaki, K. Recent progress in microstructural hydrogen mapping in steels: Quantification, kinetic analysis, and multi-scale characterization. Mater. Sci. Technol. 2017, 33, 1481-1496. [CrossRef]

15. Ohmisawa, T.; Uchiyama, S.; Nagumo, M. Detection of hydrogen trap distribution in steel using a microprint technique. J. Alloys Compd. 2003, 356, 290-294. [CrossRef]

16. Krieger, W.; Merzlikin, S.V.; Bashir, A.; Szczepaniak, A.; Springer, H.; Rohwerder, M. Spatially resolved localization and characterization of trapped hydrogen in zero to three dimensional defects inside ferritic steel. Acta Mater. 2015, 144, 236-244. [CrossRef]

17. Nagao, A.; Kuramoto, S.; Ichitani, K.; Kanno, M. Visualization of hydrogen transport in high strength steels affected by stress fields and hydrogen trapping. Scr. Mater. 2001, 45, 1227-1232. [CrossRef]

18. Ozdirik, B.; Suter, T.; Hans, U.; Depover, T.; Verbeken, K.; Schmutz, P.; Jeurgens, L.P.H.; Terryn, H.; De Graeve, I. Study of the hydrogen uptake in deformed steel using the microcapillary cell technique. Corros. Sci. 2019, 155, 55-66.

19. Schaller, R.F.; Thomas, S.; Birbilis, N.; Scully, J.R. Spatially resolved mapping of the relative concentration of dissolved hydrogen using the scanning electrochemical microscope. Electrochem. Commun. 2015, 51, 54-58. [CrossRef]

20. Evers, S.; Senöz, C.; Rohwerder, M. Hydrogen detection in metals: A review and introduction of a Kelvin probe approach. Sci. Technol. Adv. Mater. 2013, 14, 14201. [CrossRef] 
21. Evers, E.; Senöz, C.; Rohwerder, M. Spatially resolved high sensitive measurement of hydrogen permeation by scanning Kelvin probe microscopy. Electrochim. Acta 2013, 110, 534-538. [CrossRef]

22. Senöz, C.; Evers, S.; Stratmann, M.; Rohwerder, M. Scanning Kelvin probe as a highly sensitive tool for detecting hydrogen permeation with high local resolution. Electrochem. Commun. 2011, 13, 1542-1545. [CrossRef]

23. Williams, G.; McMurray, H.N.; Newman, R.C. Surface oxide reduction by hydrogen permeation through iron foil detected using a scanning Kelvin probe. Electrochem. Commun. 2013, 27, 144-147. [CrossRef]

24. Schaller, R.F.; Scully, J.R. Measurement of effective hydrogen diffusivity using the scanning Kelvin probe. Electrochem. Commun. 2014, 40, 42-44. [CrossRef]

25. Schaller, R.F.; Scully, J.R. Spatial determination of diffusible hydrogen concentrations proximate to pits in a Fe-Cr-Ni-Mo steel using the Scanning Kelvin Probe. Electrochem. Commun. 2016, 63, 5-9. [CrossRef]

26. Nazarov, A.; Vucko, F.; Thierry, D. Scanning Kelvin Probe for detection of the hydrogen induced by atmospheric corrosion of ultra-high strength steel. Electrochim. Acta 2016, 216, 130-139. [CrossRef]

27. Li, M.; Guo, L.Q.; Qiao, L.; Bai, Y. The mechanism of hydrogen-induced pitting corrosion in duplex stainless steel studied by SKPFM. Corros. Sci. 2012, 60, 76-81. [CrossRef]

28. Wang, G.; Yan, Y.; Yang, X.; Li, J.; Qiao, L. Investigation of hydrogen evolution and enrichment by scanning Kelvin probe force microscopy. Electrochem. Commun. 2013, 35, 100-103. [CrossRef]

29. Nazarov, A.; Thierry, D. Application of Volta potential mapping to determine metal surface defects. Electrochim. Acta 2007, 52, 7689-7696. [CrossRef]

30. Fuertes Casals, N.; Nazarov, A.; Vucko, F.; Pettersson, R.; Thierry, D. Influence of Mechanical Stress on the Potential Distribution on a 301 LN Stainless Steel Surface. J. Electrochem. Soc. 2015, 162, C465. [CrossRef]

31. Nazarov, A.; Vivier, V.; Vucko, F.; Thierry, D. Effect of Tensile Stress on the Passivity Breakdown and Repassivation of AISI 304 Stainless Steel: A Scanning Kelvin Probe and Scanning Electrochemical Microscopy Study. J. Electrochem. Soc. 2019, 166, C3207-C3219. [CrossRef]

32. Wang, R.J.; Lia, J.X.; Su, Y.J.; Qiao, L.J.; Volinsky, A.A. Changes of work function in different deformation stage for 2205 duplex stainless steel by SKPFM. Procedia Mater. Sci. 2014, 3, 1736-1741. [CrossRef]

33. ASTM E8/E8M-16 Standard Test Methods for Tension Testing of Metallic Materials; ASTM International: West Conshohocken, PA, USA, 2016.

34. Sato, N.; Noda, T. Ion migration in anodic barrier oxide films on iron in acidic phosphate solutions. Electrochim. Acta 1977, 22, 839-843.

35. Grosvenor, A.P.; Kobe, B.A.; McIntyre, N.S. Studies of the oxidation of iron by air after being exposed to water vapour using angle-resolved X-ray photoelectron spectroscopy and QUASES. Surf. Interface Anal. 2004, 36, 1637-1641. [CrossRef]

36. Nazarov, A.; Vivier, V.; Thierry, D.; Vucko, F.; Tribollet, B. Effect of Mechanical Stress on the Properties of Steel Surfaces: Scanning Kelvin Probe and Local Electrochemical Impedance Study. J. Electrochem. Soc. 2017, 164, C66-C74. [CrossRef]

37. Burstein, G.T.; Kearns, M.A. Accelerated Evolution of Hydrogen on Freshly Generated Metal Surfaces in Aqueous Solution. J. Electrochem. Soc. 1984, 131, 991-997. [CrossRef]

38. Lufrano, J.; Sofronis, P. Enhanced hydrogen concentrations ahead of rounded notches and cracks-competition between plastic strain and hydrostatic stress. J. Acta Mater. 1998, 46, 1519-1526. [CrossRef]

39. ISO 17081:2014 Method of Measurement of Hydrogen Permeation and Determination of Hydrogen Uptake and Transport in Metals by an Electrochemical Technique; ISO: Geneva, Switzerland, 2014.

40. Masuda, H. SKFM observation of SCC on SUS304 stainless steel. Corros. Sci. 2007, 49, 120-129. [CrossRef]

(C) 2020 by the authors. Licensee MDPI, Basel, Switzerland. This article is an open access article distributed under the terms and conditions of the Creative Commons Attribution (CC BY) license (http://creativecommons.org/licenses/by/4.0/). 